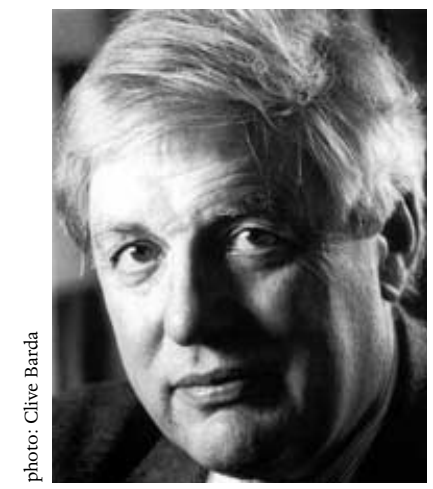

\title{
SERENADES AND ELEGIES: THE RECENT MUSIC OF HUGH WOOD - PART II
}

\author{
Edward Venn
}

Geoffrey Hill's latest book of poems, Scenes from Comus, borrows its title from Wood's op. 6, and is dedicated to the composer for his seventieth birthday. ${ }^{1}$ The two men have been friends for many years and are exact contemporaries: for the poet's seventieth birthday, Wood wrote a vocal-instrumental setting of Hill's Tenebrae. This interchange between poet and musician highlights Wood's abiding concern with poets and poetry, and particularly English verse of the 20th century. $\mathrm{He}$ has described this repertoire as 'a treasure-house, and our poets continue to produce good lyric poetry to this day: it's a waste of being English not to draw on these riches; and the composer has a particular duty to the poets of his own time'. ${ }^{2}$ More recently, Jeremy Thurlow has drawn attention to Wood's 'idiomatic and refined response to English verse: his songs for voice and piano form a considerable part of his oeuvre and must be considered the most distinctive and substantial contribution to British song-writing since Britten and Tippet'. ${ }^{3}$

In fact, about half of Wood's compositional output is vocal: mostly songs for voice and piano. ${ }^{4}$ In these, his expressive musical language is frequently paired with a poetic language of similar concentration. He has written four sets of songs to poems by Robert Graves (opp. 18, 22, 23 and 36); and he has set on more than one occasion, and amongst others, poems by Ted Hughes, Edwin Muir, D. H. Lawrence, Laurie Lee and Christopher Logue. ${ }^{5}$

Wood broke new ground in his choice of texts for the two latest additions to this repertory. The seven songs to poems by Erich Fried, op. 43, are his first settings of the German language. Another first was the use of a biblical text for the choral This is the Record of John, op. 44, offered to Wood's local church. The economy of material and directness of expression that characterize these settings can also be observed

\footnotetext{
${ }^{1}$ Hill, Geoffrey, Scenes from Comus (London: Penguin, 2005). The first 20 of these poems were published, along with a short article about Wood by Martin Anderson, in The Stand 172 Vol. $3(4) \& 4(1)$ (2002), pp. 3-23 and 25-26. While the fact that the most extensive public tributes to Wood on a major anniversary should have appeared in a poetry journal should be a cause of embarrassment to the musical establishment, it also bears elegant testimony to his enduring commitment to vocal music.

2 Composer's note to the recording of The Horses, op. 10 (1967) (see n. 4, below).

3 Thurlow, Jeremy, 'Hugh Wood' in The New Grove Dictionary of Music and Musicians II, ed. Stanley Sadie (London: MacMillan, 2001), vol. 27, 548-550; p. 549

${ }^{4}$ Recordings of Scenes from Comus and the choral The Kingdom of God, op. 38 (1995) are currently available (NMC D070 and Hyperion CDA66758 respectively). Wood's collections of songs to poems by Ted Hughes (The Horses, op. 10 [1967]) and Edwin Muir (The Rider Victory, op. 11 [1968]) were released on LP (Argo ZRG 750), but otherwise his important work in this genre remain unrecorded.

5 Over the last few years, Wood has set poems by Thomas Hardy: 'An Ancient to Ancients' and 'Thoughts of Phena at News of her Death'. He is also working on some settings of the poems of Jacques Prèvert - an old preoccupation of his. (Personal communication with the author, February 2005).
} 
in Cantilena and Fugue, op. 47 for trumpet and organ. ${ }^{6}$ However, the main work of these recent years is undoubtedly the Fifth String Quartet, op. 45 (2001).

\section{Erich Fried Songs, op. 43 (2000-1)}

On their retirement from Cambridge, Alexander Goehr and Wood exchanged musical presents. Wood's gift was to set seven songs contemplating themes of art, creativity and old age, which he drew from Erich Fried's Love Poems, a collection given to Wood by Goehr some years before. ${ }^{7}$ Dedicated to Goehr, the songs received their first performance on 7 March 2001, at the Austrian Cultural Institute.

The poems are characterized by their brevity and intensity, which in turn motivate musical settings in which Wood's already concise and expressive style is concentrated further. Music and verse combine to create seemingly straightforward songs, but just beneath the surface can be found a multitude of conflicting and complex undercurrents tenderness, irony, introspection, hope, bitterness and so on. Directness of communication is not to be confused with simplicity of message.

The opening poem, 'Gedichte Lesen', consisting of just two sentences, characterizes the concentrated writing style of the set in general. The first sentence claims that those seeking salvation from a poem ought to learn how to read poems. Conversely, the second sentence, which differs from the first only by one letter (changing 'seine Rettung' (his salvation) to 'keine Rettung' (no salvation) suggests that those expecting no salvation from a poem also ought to learn how to read poems. The underlying message is that 'poems are worth reading in themselves, even if they don't change your life'.

Example 1 is Wood's setting of the second stanza (bars 10-18), much of which is a reworking of the first stanza, but a tone higher. Bars $10-11^{1}$ and $14-15^{2}$ are direct transpositions of the equivalent passages in the first half. Furthermore, the closing cadential figure (bars 16-18) combines the melodic/harmonic content of bars $2^{3}-5$ with the cadence of bars 7-9 so as to end in D major/minor (bars 7-9 closed in the dominant A major/minor). But there are also crucial differences. Thus in the first stanza, the word 'seine' occurs as an upbeat figure; in the second, the equivalent 'keine' is given greater emphasis by being placed on the beat. The melodic profile of the phrase is also altered: instead of a diatonic fanfare-like figure for 'seine Rettung' we have instead for 'keine Rettung' an angular line rich in tritones (bars 12-13). The crucial verbal change on which the meaning of the poem hinges is given therefore highlighted by significant rhythmic and melodic changes from one stanza to the next.

${ }^{6}$ The Cantilena and Fugue and the small occasional piece Tribute to Michael Berkeley were reviewed in Tempo 59 vol. 231.

7 Fried, Erich, Love Poems trans. Stuart Hood (New York and London: Calder Publications, 1991).

${ }^{8}$ Hugh Wood, personal communication with the author, February 2005. 


\section{Example 1:}

Music (C) copyright by Hugh Wood; text reproduced by kind permission of Verlag Klaus Wagenbach GmbH, Berlin
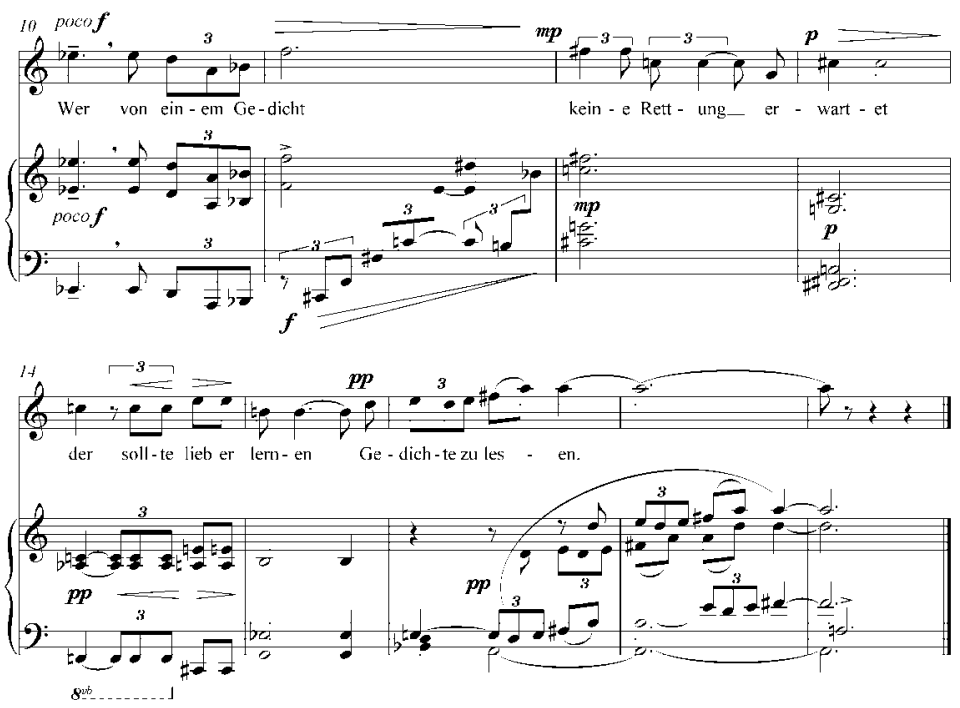

Even when repetitions from one stanza to the next are taken into account, the shifting musical contexts within the second stanza signal a sensitive, as well as an extreme, musical response to the demands of the text. Comparison with the instrumental music discussed in the first part of this article reveals a somewhat expressionist rhetoric, in which each of the four two-bar units (the last extended by a further bar) contain contrasting textures, melodic contours, harmonic density (and dissonance) and, significantly, motivic content. Nevertheless, above and beyond that conferred by the text, there exists a sense of continuity within the passage. In particular, this can be felt in the (expanded) semitonal voice-leading prevalent in the outer voices of the accompaniment: these in turn relate to the frequent semitone leanings in the vocal line. The presence of characteristic melodic motion in the vocal line (the aforementioned semitones, as well as leaps of fourths/fifths) imparts a certain sense of coherence across the otherwise fractured musical surface.

In 'Gedichte Lesen', the directness of expression of the musical setting is strongly determined by the nuances of the poem: the resulting absence of strongly defined motivic coherence represents something of an extreme in Wood's song writing. In the second song of the set, 'Grabschrift' ('Epitaph'), the opposite pole is encountered. Here, the entire vocal line is explicitly derived from a three-note motif $\left(\mathrm{B}_{b}-\mathrm{C}-\mathrm{A}_{b}\right)$; everything that follows relates to this motivic shape. Furthermore, of the 13 motivic repetitions that constitute the vocal line, eleven are direct transpositions of the opening figure to begin on either $\mathrm{B} b, \mathrm{C} \#, \mathrm{G}$ or $\mathrm{E}$ natural. The transposition of the motif onto these four pitches alone ensures all the notes of the chromatic scale are brought into play. ${ }^{9}$

\footnotetext{
9 The initial ordering of these transpositions - beginning on $\mathrm{B} b$, E, C\# and G respectively serves further to parse this chromatic gamut into two whole-tone sets. Although this bifurcation does not appear to have further structural ramifications within the song, it should nevertheless be noted as an instance of Wood drawing on such modes to organize his material (his later music is increasingly likely to draw on pre-existent modes as a kind of objet trouvé).
} 
The composer instructs the singer to deliver his/her line in an 'ironic' fashion, and we can assume that the motivic saturation, lacking Wood's characteristic subtlety, is a musical corollary to the required mode of performance. However, although the motivic repetitions act as a pitch constraint, they enable the freeing-up of other aspects of the music. For instance, in responding to the micro-rhythms demanded by the poetic text, Wood does not repeat the rhythm of a single bar in the vocal part. ${ }^{10}$ The dynamic interaction between musical structure and textual demands is intensified midway through song, when, speaking of the hunger of the poem's protagonist (who chose his art before bread), the poem mentions 'no cook at all, for there was no broth to spoil'. At this crucial point of the poem, the motif is transposed to begin first on $\mathrm{E}_{b}$, then $\mathrm{A}$ (i.e. the only two transpositional levels not beginning on the underlying diminished seventh), with the fall of the major third between the final two notes of the motif contracted to a minor third. This slight change - a considerable deformation in the context of the song -initiates a series of imitations in the piano that releases the piano from a purely accompanimental role, thus emphasizing the content of the text. In this way, what appears at first to be 'ironic' and uncharacteristic motivic repetitions (which assert and assure musical coherence) are revealed to be an intimate and intrinsic part of the musical response to the poem.

By way of demonstration of the wide variety of expressive devices and the technical means displayed within the set, two further examples will have to suffice. The carnivalesque atmosphere of the fifth song, 'Homeros Eros', is achieved through the simplest of means: an extended prolongation of a B flat major chord and the superimposition of a $5 / 8$ piano right hand over the $3 / 4$ of the voice and piano left hand. Combined with a throw-away ending, which punctures the mood with what appears to be an exaggerated raising of the eye-brows, the song reveals a light-heartedness that rarely finds a place in Wood's music, but is all the more telling when it does so. ${ }^{11}$

The final song, 'Vielleicht' ('Perhaps'), is the longest of the set, and to my mind the finest. In its clarity of texture, material and means of expression, it embodies the general tendencies of the set as a whole. Its words express how art has the capacity to remain long after its creator's death, motivating one of Wood's most contemplative settings. The opening stanza is given in Example 2. The harmonic motion of the passage as a whole, which gently shifts from a diminished triad on D towards B flat, might better be thought of as a slowly evolving harmonic field around a focal D. Combined with the motivic echoes and pre-echoes of the voice in the piano part, and the softly stumbling rhythms, the impression in bars 1-6 is one of expansiveness, and of reflection. The second half of the setting (bars 7-13) is also notable for one of Wood's signature melodic shapes: a lyrical series of alternating rising major thirds and falling semitones. This shape appears twice, each time forming a complete octatonic set. A second octatonic set (on 'überdauern') contains both a diminished triad on D as well as a B flat major chord: the octatonic set thus contains and summarizes the harmonic motion of the stanza. Once again, we are confronted with simplicity of means, but, as with all the songs in the set, the end results are both subtle and sophisticated.

\footnotetext{
${ }_{10}$ The use of free rhythmic development to contrast with repeated pitch structures suggests a parallel with Schubert's Der Döppelganger.

11 A similar ending can be found in Wood's Piano Concerto, op. 32 (1991).
} 

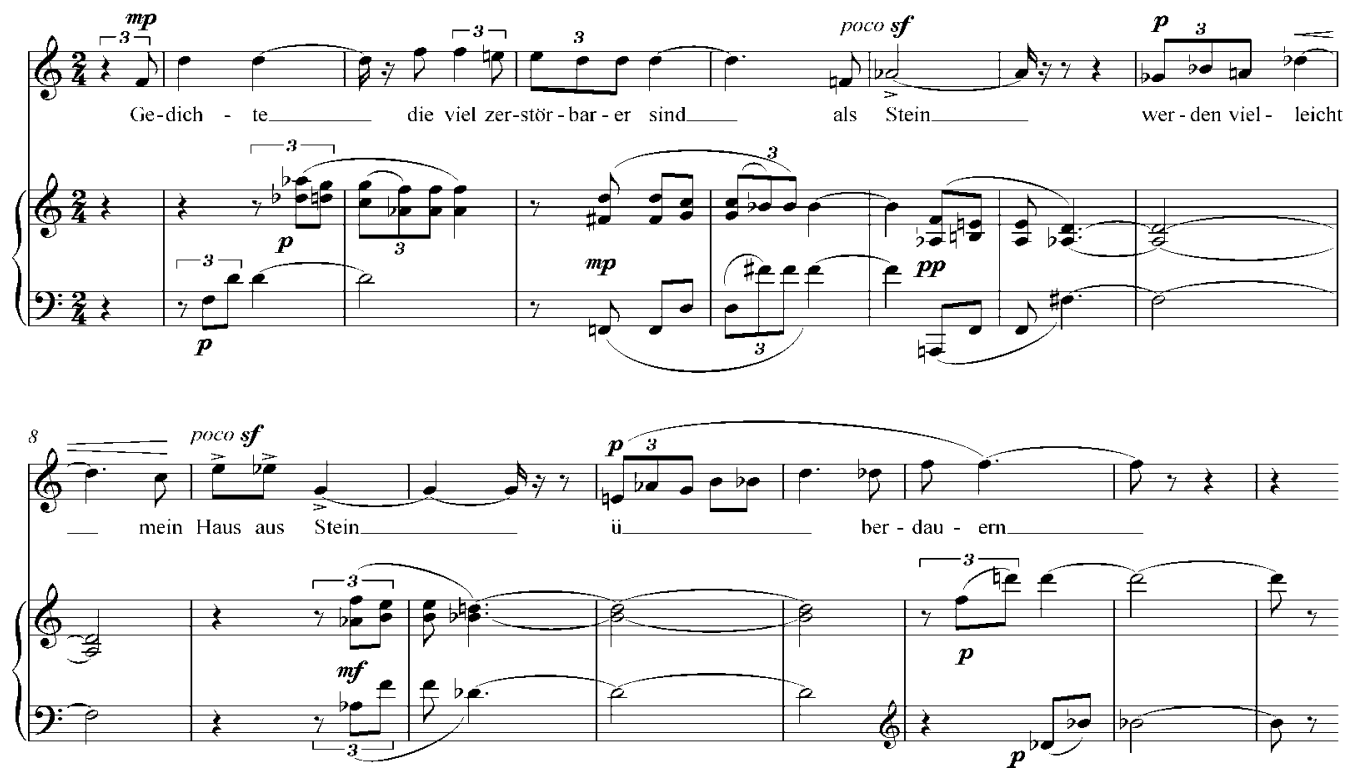

\section{Example 2:}

Music (C) copyright by Hugh Wood; text reproduced by kind permission of Verlag Klaus Wagenbach GmbH, Berlin
This is the Record of John, op. 44 (2001)

This is the Record of John, a setting of John 1, 19ff, was written for unaccompanied SATB to mark the Reverend Prebendary John Slater's departure from St. John's Church, St. John's Wood. An occasional work, the piece nevertheless demonstrates Wood's fluency in creating well-balanced musico-dramatic structures.

In keeping with the nature of the text, the work falls into three sections. The first is a short introduction, setting the words 'This is the Record of John / when the Jews sent priests and Levites from Jerusalem to ask him / Who art thou?' The musical language is initially diatonic ( $\mathrm{C}$ major), and largely triadic, with frequent added notes (particularly sevenths and ninths). Only with the question at the end of the section - a fortissimo statement in octaves - is the first non-diatonic note introduced (a C\#). This question, and the corresponding ruptures to the musical language, set in motion a series of dramatic interchanges that form the second section of the work. Here, the musical language changes to a more chromatic idiom; the textures also become more fragmented as the textual dialogue intensifies. John is represented initially by a solo bass voice. Each of his first three answers he gives to the chorus's questions ends a semitone lower than the one before (descending from $\mathrm{F} \#$ down to $\mathrm{E}$ natural); these bass notes function as points of reference within the section as a whole.

The second section ends with the fourth question of the chorus, 'What sayest thou of thyself?'. John's answer is first given to a solo tenor ('I am the voice of one crying in the wilderness'; its continuation is swiftly taken up and developed polyphonically by the whole choir ('Make straight the way of the Lord/ Amen'. The musical language of this third and final section returns to the diatonicism of the first, albeit greatly extended. In total, the final section accounts for roughly half the work's length, and acts as a musical and emotional counter-balance to the drama of the second section.

Comparison with the final section of Serenade and Elegy, ${ }^{12}$ Wood's other work to make use of such extended diatonicism, illuminates the

12 For more on Serenade and Elegy, see part one of this article (Tempo Vol.59 No. 231, pp. 2-13). 
relationship between diatonicism and tonal function in This is the Record of John. In Serenade and Elegy, the unambiguously C major context of its Pfitzner quotation is marked by regular (if gentle) perfect cadences. The use of diatonicism enhances the affective qualities of tenderness and innocence, and it is into this diatonicism that Wood's bittersweet chromatic superimpositions are gradually absorbed. In contrast, although the rhythmic and textural foreground of the final section of This is the Record of John evokes traditional patterns of closure, it is not supported with comparably unambiguous tonal references: it is 'on' rather than 'in' C. Thus, unlike much of Wood's music, the tonal allusions do not gain their force from their fleeting, fugitive or momentarily beguiling nature. Rather, because situated in an extended diatonic (and thus potentially tonal) context, such events are rendered significant through their distance or proximity to traditional tonal models. For instance, the closing section (bars 33-51) can be characterized by an avoidance of a strong leading note: the one instance of a $B$ rising directly or indirectly to a $C$ is not supported by a dominant-tonic harmonic progression (bars 37-8; tenor voice). As the passage progresses, linear motion in the bass begins to assert a clearer tonal background, moving towards a dominant pedal (bb. 43-7). But this ends with an ambiguous sixth over the pedal (suggesting a 6/4 chord) that does not 'resolve' to the expected dominant chord. Instead, there is an implied plagal cadence (bb. 48-51; to the word 'Amen'), in which the concluding ' $\mathrm{C}$ major' chord is in second inversion with added sixth and ninth. ${ }^{13}$ The result is a musical language that is delicately balanced between meandering diatonicism and directed tonal motion: by achieving this balance, the work achieves expansiveness and familiarity of expression but without direct recourse to traditional gestures.

\section{Cantilena and Fugue op. 47 (2004)}

The Cantilena and Fugue for trumpet and organ was commissioned by Deborah Calland and premièred at the City of London Festival. The basis of the Cantilena is a broad theme first announced by solo trumpet. The contours of this theme (though not all of the detail), transposed down a tone, are given at the foot of Example Three as the note-row ' $\mathrm{P}_{10}$ '. The semitones between notes six and seven, and again between ten and twelve, give some indication of the strong sense of linear motion that characterizes the theme.

The actual music of Example 3 is the organ entry that immediately follows the trumpet solo. Here, one can see the clear patterns of expansion within the phrase, beginning with a two-bar idea in which three notes rise through a fifth (labelled $x$ in the Example). The next three bars consist of a rise through a diminished octave $(y)$; the next four rise through an augmented sixth and then onto a major seventh $(z$; the 'final' major seventh is indicated by the dotted line). A comparison between the given registers and the outline pitch structure at the foot of the Example reveals that the original trumpet line has been fragmented into its constituent motifs, and then separated into different octaves. Thus the gradual ascent that characterizes the trumpet phrase is replaced by a staggered descent that, at its extremes, encompasses nearly three octaves. Such an expansion provides contrast with the opening trumpet line, as well as preparing for the addition of the organ pedals in the subsequent phrase.

13 The fourth in the bass - usually evoking a 6/4 chord - is a recurring characteristic of Wood's music. 

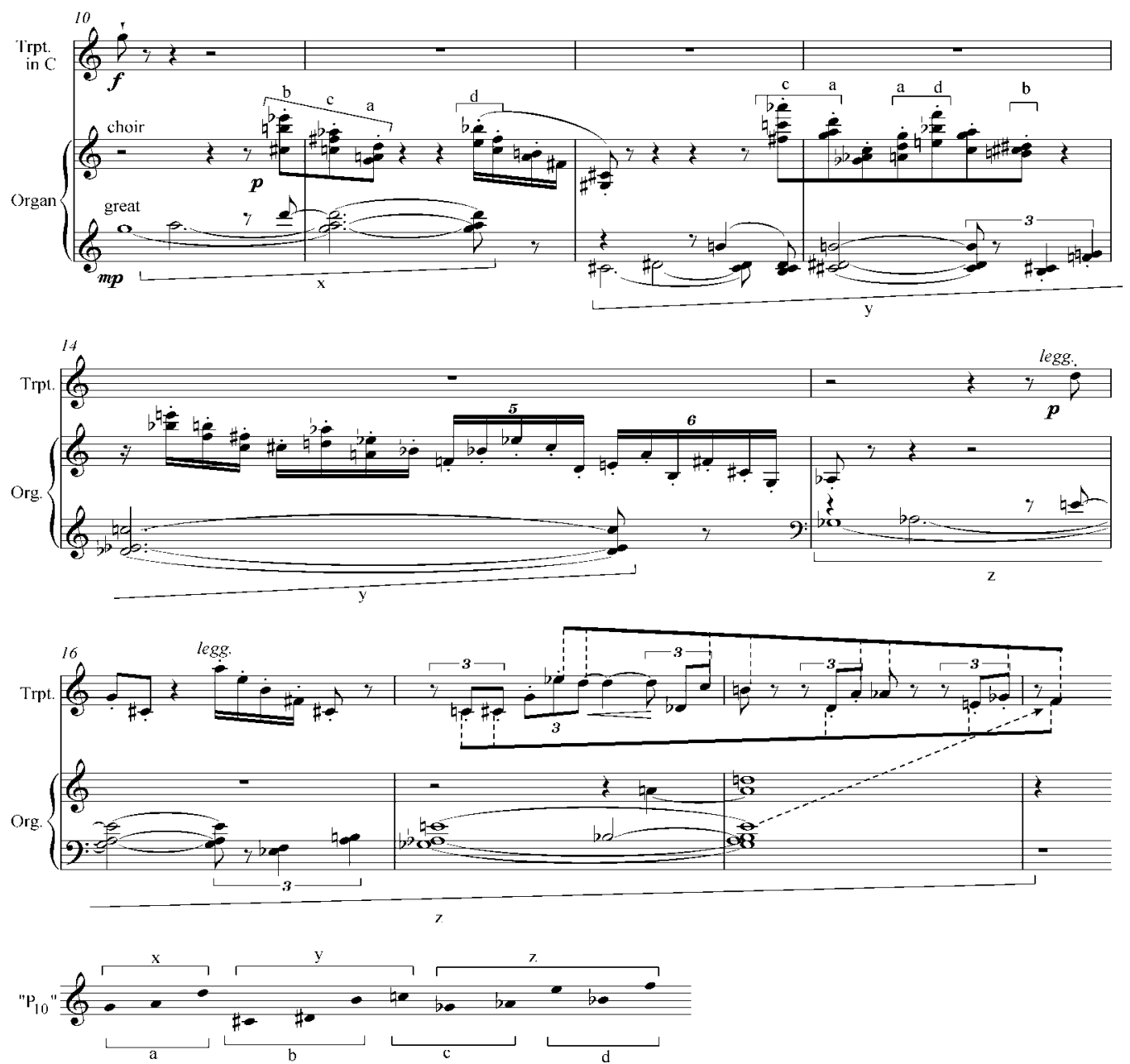

Example 3:

(C) Copyright 2004 Chester Music Limited. All Rights Reserved. International Copyright Secured. Reprinted by permission
The chords in the right hand of the organ part are initially derived from a straightforward segmentation of the 'row', as can be seen in the Example. Nevertheless, it is the line in the upper voice of these chords that is taken and freely developed as a counter-melody. Indeed, the essence of Wood's musical argument is frequently - as here - the progressive (non-serial) elaboration of such cells and the generation of related material. Continually underpinning this free development, the slower-moving theme in the organ left hand functions almost in the manner of a cantus firmus. The final note of the theme is not given to the organ, but rather is reached via a compound melody in the trumpet that approaches it via contrary motion (see the beams added to the example). The F reached in the trumpet initiates a rhythmically contrasted 'second subject' based on the same pitch material as the original row. (The organ pedals provide a new 12-note countermelody.)

What follows is formally simple, but crucial in determining the character of the music: a mini-development and climax, a varied recapitulation and a final statement of the opening theme, at original pitch, for solo trumpet. This can be understood as a sonatina, a view supported by the generally lyrical character of the material, and by the absence of dramatic oppositions. The initial theme frequently recurs 
to either provide, or underpin, the musical argument; more often than note the end of one statement is elided with the start of the next. This can be seen at both the start and end of Example Three, and correlates with Wood's practice of using complete thematic statements as a means to articulate form. Such economy makes the Cantilena one of Wood's most concentrated works since the Quintet, op. 9 (1967). ${ }^{14}$ That this concentration should occur in a work of lyric fantasy, whose surface charm belies the rigour of its working, is typical of this composer.

The lyricism of the Cantilena stands in contrast to the brashness of the subsequent Fugue. The widespread 12-note working of the first movement is also notably absent in the latter: after a chromatic threenote incipit, the fugue subject spirals off into strings of ascending fifths and descending fourths. ${ }^{15}$ Before the exposition finishes, the theme is presented in regular crotchets that cut across the underlying $6 / 8$. This points to two of the most endearing characteristics of the movement: a cheerful rhythmic vitality and a staunchly non-academic treatment of fugal procedures. The first episode begins with a motif derived from the fugue's incipit, and there is a stretto in the middle entries. There then follows two greatly augmented versions of the theme in dotted minims: first on the organ pedals (bar 30) and then in bar 32 in the trumpet. After a second episode the subject appears in inversion in another stretto. Suddenly, the fugue is abruptly cut off to make way for a coda, announced by rumbling quavers in the organ pedals and making use of dramatic discourse between sprightly organ chords and driving trumpet arpeggios. The subject appears briefly just before the end, shared between organ and trumpet, by way of closure. Such are the facts of the fugue, but dry description cannot convey the energy of the movement: this is Wood at his contrapuntal best.

\section{String Quartet No. 5, op. 45 (2001)}

Wood's most significant contribution to the chamber music repertoire is undoubtedly his string quartets. The Fifth and most recent was first performed in October 2001 by the work's dedicatees, the Lindsay Quartet. ${ }^{16}$ With Bartók's Fourth Quartet as an obvious model, Wood's Fifth Quartet is in five movements, arranged symmetrically around the slow movement, a Romanza. Wood's long interest in the scherzo gives rise to two Nocturne-Scherzi, placed either side of the Romanza. Of the outer movements, the first loosely corresponds to a sonata-allegro (see below), the last to a rondo: these are roughly equal in weight, and give greater emphasis to the symmetrical construction of the work. ${ }^{17}$

The first movement of the Fifth Quartet provides a concise example of the sort of synthesis and refinement of technical, aesthetic and expressive aspects of Wood's language that is typical of his later music. Through its juxtaposition of contrasting ideas, one is reminded of the agglutinative forms that typify his Second and Third Quartets, and the

\footnotetext{
${ }^{14}$ Of works of this nature, Leo Black has written that Wood 'works his basic material very hard indeed: $[\ldots]$ The resulting obsessed quality is moving, and uneviable: one would not care to see those one admires forced into such risk-taking too often'. See Black, Leo, 'The Music of Hugh Wood', Musical Times vol. cxv, 115-7, p.116.

15 Those keen on establishing links between movements may look to the countermelody of, say, bar 16 of Example Three as a local precedent for these fourths.

${ }^{16}$ Strictly speaking, this is Wood's sixth quartet, but the early String Quartet in B flat (1956-7; see part I of this article) is unnumbered.

17 This differs from Wood's usual (Beethovenian) practice in multi-movement works, in which the centre of gravity is generally placed in the finale. The First and Fourth String Quartets, both with four movements, are good examples of this.
} 
opening movement of the Fourth. ${ }^{18}$ The Second Quartet is a particularly interesting precedent, for the central section of its overall ternary design sees an alternation of scherzo elements with ideas of a slow movement character. In the first movement of the Fifth Quartet, the alternating ideas are that of a sonata-allegro first idea and second idea: one visceral and gestural, one lyrical and contrapuntal. The 'mosaic' form fragments and intensifies the sonata dialectic, not least through the omission of transitions. Despite this fragmentation, the skeleton of a three-part form can be detected, the final section a compressed recapitulation in which the second subject is omitted. Further evidence of a suppressed (or distorted) sonata background can be detected in the second section, which also contains elements signifying traditional developmental elements. The visceral first idea becomes an energetic fugue; the lyrical idea evolves into a 'new' theme, which is also contrapuntally treated. The tensions between the suppressed background and energetic, dramatic and fragmented foreground contribute to the exhilaration of the movement. It is entirely typical of the composer that the fundamental formal questions that arise - namely, how to generate coherence in a work that is characterized by discontinuity are dealt with intuitively, rather than through systematic means.

The scherzo-writing of the second and fourth movements must count among Wood's most macabre. For the most part, they present material in hushed whispers - scurrying lines constructed from chromatic clusters, often in imitation or even canon - and any dynamic climaxes are swiftly stifled. Contributing to the fugitive atmosphere is the evasion of lyricism, coupled with a general avoidance of normal string tone. This latter tendency is particularly marked in the second scherzo, in which all the material is either played as harmonics (or flautando), pizzicato, or col legno. The emotional world occupied by these movements is far removed from the high spirits of the scherzo in the Clarinet Trio, or the barely-restrained impulse to dance of the scherzo variations in the Variations for Orchestra. Instead, they have more in common with the scherzi in Wood's Song Cycle to Poems by Pablo Neruda, op. 19 (1974) but rather than evoke the haziness of summer and the hum of the bees (as in the Neruda songs), the quartet movements conjure up something far more sinister, more spectral. These are Nocturnes in which the moon, if present at all, is closer to Pierrot Lunaire than Clair de lune.

In naming the central movement Romanza, Wood draws our attention to the fact that he has composed a relatively light slow movement, unlike the deep and intense Adagios of works such as the Fourth String Quartet and the Symphony. Such a designation captures the mood of the movement, as well as the nature of the material. The movement can be divided into two 'stanzas', of which the second is a re-working of the first, followed by a brief coda. The two stanzas can each be divided into a further three sections. The first of these sections is introductory; I will return to them below. The second consists of a lyrical melody: in the first stanza this is given to violin I (bb. 12-20); in the second, a decorated version is given to the cello (bb. 55-68). Although each of these instruments continue to dominate in the third section of each stanza (respectively, bb. 21-42 and 69-79) there is greater emphasis on contrapuntal working in the accompaniment. At

18 The precedent for this was, according to Wood, was Stravinsky's Symphonies of Wind Instruments, which presented a 'formidable challenge to all [Wood's] formal conceptions' (Composer's note to String Quartet No. 2, op. 13 [1970]). Wood's particular application of this method, though, seems to me to owe as much to the juxtapositions of Beethoven's late quartets. 
Example 4:

(C) Copyright 2003 Chester Music Limited. All Rights Reserved. International Copyright Secured. Reprinted by permission the end of the first stanza, this working leads to a climax; at the end of the second, a warm coda in which violin I dominates once more. There are numerous instances in Wood's chamber music output where individual instruments are given extended melodic lines: the Piano Trio op. 24 (1984) and the Clarinet Trio op. 40 spring most readily to mind. However, this is the first time Wood has used this device in a string quartet. By positioning a movement with such a direct (and simple) manner of communication after the densely-organized and suffocating sound world of the first Nocturne-scherzo, the effect is dramatically and affectively powerful.

The material of the Romanza is as straightforward as its overall form. Nowhere is this more apparent than in the introductory sections to each stanza. The lyricism and delicacy of the opening of the movement (Example 4) is in no small part due to its faux-naiveté. The main materials are deceptively simple: the upper line largely based on descending whole-tone scales, and contrapuntal lower voices that abound with figures based on the contours of motif $x .{ }^{19}$ There is also a seemingly unsophisticated use of sequence: a direct transposition of material between the first and second phrases, and, to generate the pitch material of the third phrase, a second transposition of the wholetone line. There are, of course, subtleties that reveal this to be a calculated artlessness, such as the rhythmic transformation of motifs and the placing and combination of material.

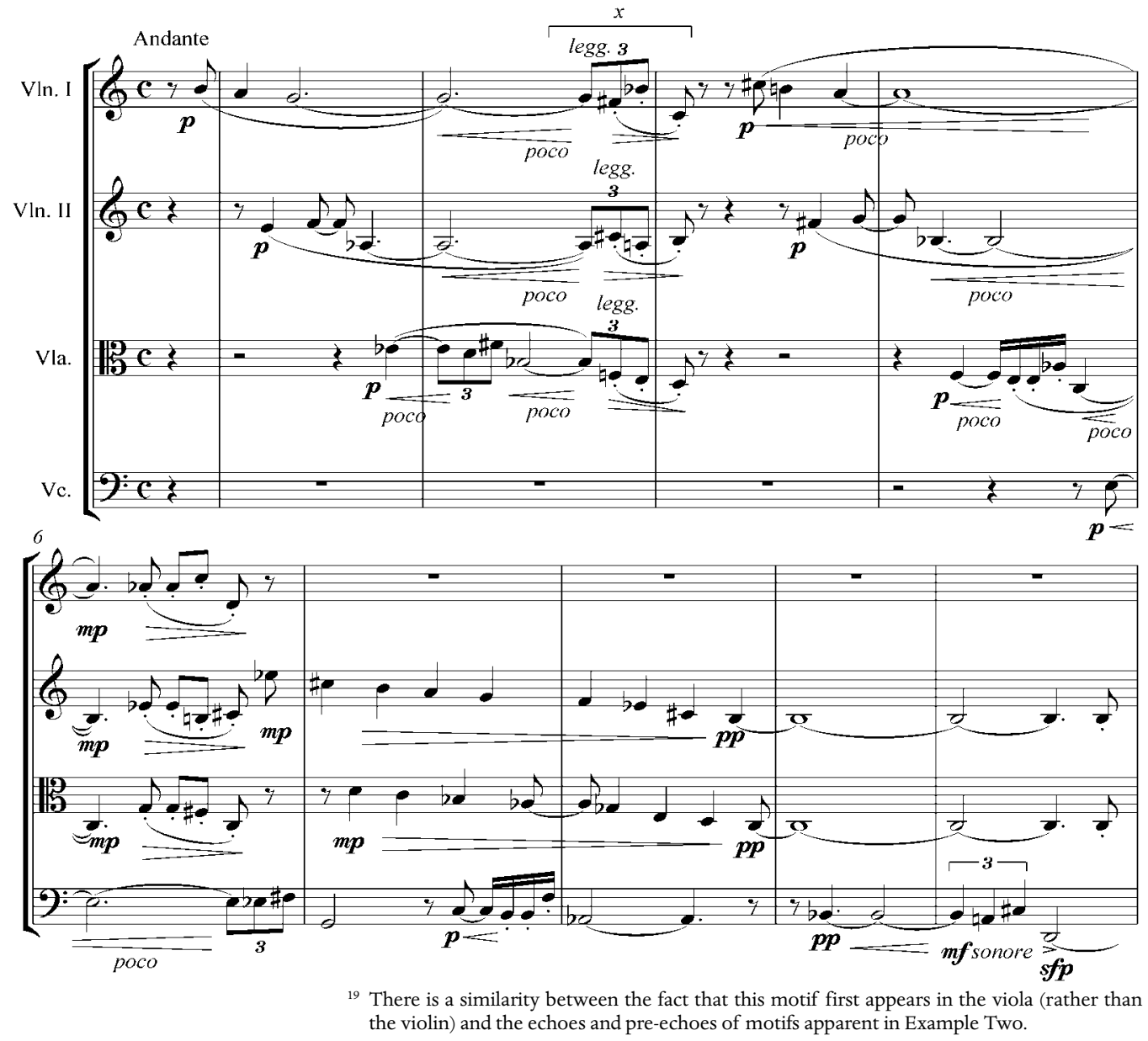


Example 5:

(C) Copyright 2003 Chester Music Limited. All Rights Reserved. International Copyright Secured. Reprinted by permission
On its reappearance at the start of the second stanza, the material of Example Four undergoes substantial re-working (see Example Five). Comparison between bars 1-2 of Example Four and bars 43-45 reveal that the opening phrase has been fragmented and re-ordered, so that material appears in different parts (e.g. the line originally given to the second violin now appears in the cello part) and with different rhythmic implications. An addition of a new element - the viola line of bars 43-45 - alludes to a different harmonic interpretation. For the second phrase, only the descending whole-tone segment survives from one stanza to the next, and in the third, the concluding harmony of bar 9 (which is also present in bar 3) is given greater importance in bar 49. There is something touching and elegant about the way Wood can imbue material that is almost banal in its first appearance with such significance and expressiveness.
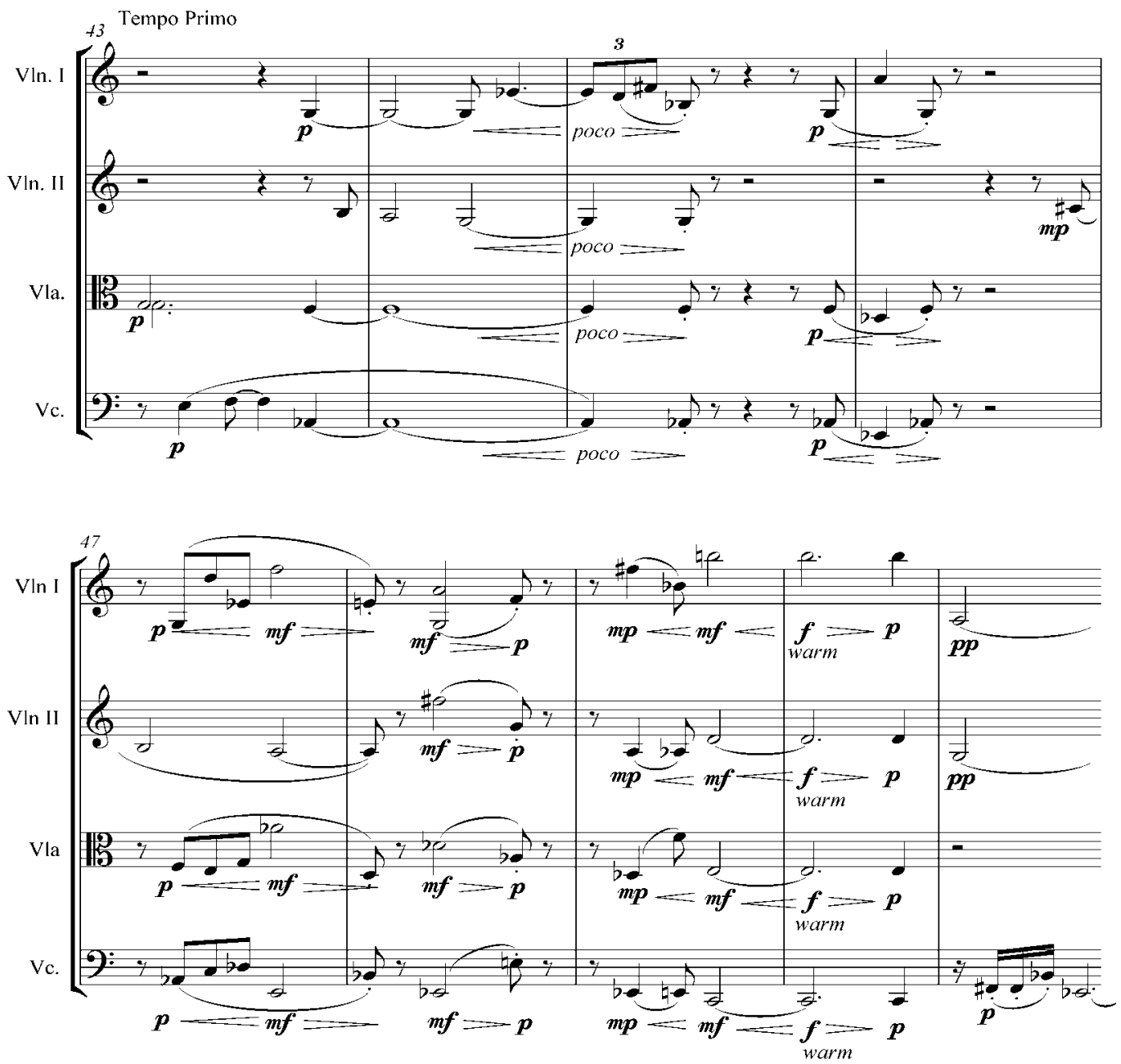

The final movement, 'a sort of rondo', ${ }^{20}$ opens with a direct reference to the first theme of the first movement. But this proves to be playfully misleading, for it is not this theme, but rather the homorhythmic figure in the second violin, that provides the basis not

${ }^{20}$ Composer's note to the score. 
just for the rondo theme, but the first episode too. The inventiveness resulting from the extended focus on a single idea, coupled with the buoyant rhythmic impetus, reminds one of Haydn finales. As is increasingly the norm in Wood's later music, the recapitulation of material is compressed, often through elision or juxtaposition of material. The resulting shifting of textures and moods brings the quartet to a lively dramatic close, rather than the weighty solutions offered in many of the composer's previous works.

In the light of Hugh Wood's recent music, it is possible to speculate on future developments? Except for the banal answer that the technical procedures and aesthetic stance exemplified by these works will doubtless continue to inform his music, no single trend can be isolated. As ever with this composer, numerous and seemingly conflicting impulses co-exist, sometimes within the span of a single work. Thus the asceticism of, say, some of the early variations in op. 39 finds a place next to the romanticism of the later ones (in particular, the tenth variation). For every densely chromatic and dissonant statement, such as the first Nocturne-scherzo of the Fifth Quartet, we can find the warmth and lyricism of the Romanza. And so the list goes on. Wood's language is rife with these seeming contradictions, and, in a true modernist vein, his work does not shy from celebrating such discrepancies. But what distinguishes Wood is his continued desire to explore ways of making connexions between disparate states, to find ways of communicating human values whilst acknowledging the fractured nature of human life. ${ }^{21}$ In this light, Wood's expressive and sincere musical language gains an urgency and significance that we are illadvised to ignore.

\footnotetext{
${ }^{21}$ Wood has articulated these concerns in 'A Photograph of Brahms', in The Cambridge Companion to Brahms, ed. Michael Musgrave (Cambridge: Cambridge University Press, 1999), pp. $268-287$.
} 